\title{
Hermenêutica filosófica como filosofia prática
}

\section{Philosophical Hermeneutics as pratical philosophy}

DOI: http://dx.doi.org/10.12957/ek.2015.16826

Dnda. Viviane Magalhães Pereira vivianefilosofia@yahoo.com.br

PUC RS - Brasil | Albert-Ludwigs Universität Freiburg - Alemanha | CAPES

Pretendemos desenvolver neste artigo a tese de que a hermenêutica filosófica de Hans-Georg Gadamer é uma filosofia prática. Trata-se de mostrar, em primeiro lugar, qual argumento central sustenta tal ideia e, em segundo lugar, de revelar a influência grega, especialmente de Aristóteles, que está por trás da proposta de universalidade da hermenêutica. Portanto, defenderemos brevemente aqui o que caracteriza a hermenêutica como um modo de se fazer Filosofia, que é, antes de tudo, prático e traz a radical necessidade do debate da problemática da ética.

PALAVRAS-CHAVE hermenêutica . filosofia prática . Gadamer

The aim of this paper is to develop the thesis that Hans-Georg Gadamer's philosophical hermeneutics is a practical philosophy. It is a matter of showing first of all which central argument supports such idea and secondly the Greek influence, especially from Aristotle, behind the universality-claim of hermeneutics. The purpose here is therefore to show what characterizes hermeneutics as a way of doing philosophy, which is above all practical and brings the radical need of debate on ethical issues.

KEYWORDS hermeneutics . practical philosophy . Gadamer 


\section{Introdução}

A hermenêutica de Hans-Georg Gadamer possui uma especificidade ante as outras hermenêuticas: ela pretende elevar-se à condição de uma teoria filosófica. Isso significa defender que o fenômeno da compreensão possui uma universalidade e que somos capazes de pensá-lo a partir da perspectiva do conceito. Podemos resumir tal tese gadameriana com esses dois argumentos centrais: a compreensão é condicionada tanto historicamente, o que pode ser representado pelo conceito de "história continuamente influente" (Wirkungsgeschichte), como pela relação com um "outro", o que pode ser mostrado por meio do conceito de "aplicação" (Anwendung). Nisso reside o sentido mais próprio de tomarmos a hermenêutica filosófica por uma filosofia da finitude. Nossa compreensão é limitada, por um lado, pela linguagem que adquirimos no contato com a tradição histórica e, por outro, pelo nosso diálogo com o outro.

Gostaríamos de tratar brevemente neste artigo do segundo argumento acima mencionado. Aí nos parece que a hermenêutica filosófica tende muito mais para uma filosofia prática, do modo como surgiu em meio à filosofia grega, do que para a tradição hermenêutica que lhe precedeu e cujo debate se aproximou mais vivamente de Gadamer através da figura de Martin Heidegger e sua fenomenologia hermenêutica. Nesse sentido, os estudos de Gadamer sobre Platão e Aristóteles marcaram de forma muito mais significativa o seu pensamento. Eles contribuíram de diversos modos, ao longo da sua trajetória filosófica, para constituir o que consideramos ser não apenas uma dimensão da hermenêutica filosófica, mas, antes de tudo, o seu modo próprio de refletir sobre várias questões filosóficas: ela é uma filosofia prática. Isso significa afirmar, em primeiro lugar, que ela é um modo especial de se fazer Filosofia, ou seja, que ela propõe uma abordagem diferenciada para os temas filosóficos, que é, antes de tudo, prática e traz a radical necessidade do debate da problemática da ética.

\section{A retomada da filosofia prática: aplicação e diálogo}

Schleiermacher definiu a hermenêutica como "a arte de compreender corretamente o discurso de um outro" e ainda acrescentou: "Somente arte da compreensão, não também apresentação" (SCHLEIERMACHER, 2005, p. 91) (aplicação). Explicação essa que remontava, implicitamente, a uma divisão que existiu, antes de Schleiermacher, com a hermenêutica teológica e com a hermenêutica jurídica, do problema que envolve a hermenêutica em três 
momentos, a saber, da compreensão (subtilitas intelligendi), da interpretação (subtilitas explicandi) e da aplicação (subtilitas applicandi). Contudo, a hermenêutica recebeu um significado sistemático justamente com Schleiermacher, que reconheceu a unidade interna entre compreender e interpretar, chamando a hermenêutica de "arte de compreender" e não de interpretar. É tanto que, ao tomarmos como base de nossas considerações o paradigma hermenêutico, nós costumamos utilizar, em quase todos os casos, os termos "compreensão" e "interpretação" de forma indiferenciada.

Como Gadamer mesmo afirmou: "Interpretação não é um ato posteriormente e ocasionalmente complementar à compreensão, por outro lado, compreensão é sempre interpretação, e, assim, interpretação é a forma explícita da compreensão" (GADAMER, 1990, p. 312). Acontece que, ao darmos demasiada atenção a esses termos, acabamos por negligenciar o conceito de "aplicação", não porque concordamos com a ideia de Schleiermacher de que a "apresentação" seria somente "uma parte especial da arte de falar e de escrever" (SCHLEIERMACHER, 2005, p. 91), mas em razão de naqueles termos residirem a centralidade dos questionamentos da hermenêutica. Isso também ocorre porque, quando se fala em compreensão e aplicação, logo se imagina que se trata de utilizar a compreensão de algo com alguma finalidade prático-técnica, como a aplicação de uma lei ou a aceitação de uma regra para as atividades cotidianas. A hermenêutica moderna, representada principalmente por Schleiermacher, evitou falar de hermenêutica como uma forma de aplicação justamente porque não queria que ela fosse igualada a uma espécie de técnica.

No entanto, quando Gadamer fala em aplicação, ele a entende de outro modo. Trata-se de admitir, por um lado, que a compreensão sempre exerce uma espécie de influência sobre algo, seja sobre si mesmo, o outro ou o mundo e, por outro lado, que ela depende dos efeitos de uma linguagem a ela exterior, do distanciamento de si mesmo, da escuta do outro, do diálogo. De um modo ou de outro, a interpretação surge na relação com um outro e se mantém através dos efeitos que aí atuam reciprocamente, podendo gerar e transformar os significados das palavras que integram a nossa forma de ver o mundo. Nesse sentido, temos que reconhecer que não somente a compreensão e a interpretação fazem parte de um processo unitário e integrante, mas também a aplicação. Segundo Vattimo, é precisamente:

[...] na identificação entre interpretar o mundo e transformá-lo (atuando historicamente) assim como, sobretudo, na identificação entre compreender [a si mesmo 
e ser alguém que atua,] reside, provavelmente, um dos núcleos [...] da hermenêutica de Gadamer (VATTIMO, 2003, p. 61).

Aqui se encontra uma das justificativas que torna possível o reconhecimento da hermenêutica como filosofia prática ${ }^{1}$. Para Gadamer, toda criação e toda ação humanas dependem muito mais do modo como atuamos, como aplicamos a linguagem que herdamos da tradição, como nossa relação com o outro acontece, do que daquilo que fixamos por escrito ou consideramos que deveria ser feito. As tensões entre vida e morte, interior e exterior, passado e futuro, domínio e subjugação, amigo e inimigo, fazem de nossa interpretação algo fundamentalmente do âmbito prático, na medida em que aparecem nas formas variadas em que se dão concretamente as relações entre os seres humanos ${ }^{2}$.

Não é o conhecimento puramente teórico desses polos opostos o decisivo para a nossa compreensão. O que determina o que poderá ser compreendido é o modo muitas vezes imprevisível como aquelas tensões se manifestam no uso das palavras, no diálogo com os outros, na reação ante o choque de um acontecimento novo. Tais manifestações não são tão óbvias quanto parecem em um primeiro momento. Elas carregarem consigo história, preferências, expectativas e, como tal, fazem referência a algo mais do que aquilo que imediatamente aparece. Ademais, aqui também entra em jogo tudo o que somos capazes de transformar com cada troca de pontos de vista, interpretação, decisão.

Por essa razão, caso pretendamos compreender algo adequadamente, precisamos compreendê-lo em cada situação concreta de uma maneira nova e distinta. Aqui, compreender pressupõe uma aplicação, um sentido para o prático, para o que nos acontece ${ }^{3}$. Desse modo, compreender, interpretar e aplicar são uma coisa só, a qual a hermenêutica gadameriana chama simplesmente de compreensão. Nenhum sentido é um horizonte fechado, porque o momento da compreensão é, mesmo que às vezes de maneira imperceptível, um momento de reconhecimento do outro e de transformação das coisas e de nós mesmos.

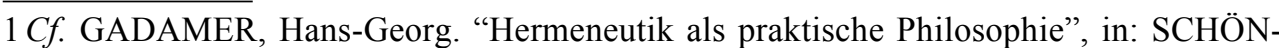
HERR-MANN, Hans-Martin (Hrsg.). Hermeneutik als Ethik. München: Wilhelm Fink Verlag, 2004.

2 Cf. GADAMER, Hans-Georg. "Historik und Sprache" [1987], in: Hermeneutik im Rückblick. Gesammelte Werke, Bd. 10. Tübingen: Mohr Siebeck, 1999, p. 328.

3 Cf. GADAMER, Hans-Georg. Wahrheit und Methode, p. 314. 
Na história não estamos frente a uma série de fatos que basta constatar, mas somos atingidos diretamente por aquilo que estamos conhecendo. No estudo da Filosofia, por exemplo, vemos que a compreensão de um tema implica necessariamente em uma transformação do próprio pesquisador, pois, compreende melhor uma questão, a qual envolve especialmente a própria experiência humana, aquele que na sua experiência particular se deparou concretamente com situações que lhe exigiram a compreensão do problema em questão e que com isso aprendeu algo.

A compreensão não se reduz a um procedimento isolado de uma consciência que capta abstratamente o sentido de alguma coisa, nem muito menos uma aplicação plenamente consciente de um conhecimento à realidade ${ }^{4}$. Do contrário, ela é uma práxis, isto é, está ligada a todos os comportamentos humanos e à auto-organização humana neste mundo ${ }^{5}$. Quem compreende age de alguma forma, seja transformando a si mesmo, seus ouvintes ou o conteúdo daquilo que é compreendido. É por isso que interpretar é perigoso. Em primeiro lugar, pomos em risco não somente o que sabemos da tradição, mas também sobre nós mesmos, uma vez que não podemos nos abster do fato de termos que participar, isto é, estar envolvidos no momento da compreensão, implicados no sentido percebido ${ }^{6}$ e igualmente submetidos a questionamentos. Em segundo lugar, possuímos um sentido para o tempo, ou seja, para o correto e o incorreto e, assim, no caso de um mal-entendido, podemos transformar o mundo orientados por um projeto equivocado.

Apesar desse perigo que toda interpretação representa, nela vem à tona algo diferente, ou melhor, um acréscimo de sentido ao que já era conhecido, que nos dá justamente a chance de correção do que antes supúnhamos ser verdadeiro. É que não há, no uso de uma língua, identidade pura entre uma palavra e um elemento significativo preciso. A diferença se encontra na identidade, na medida em que a linguagem é mobilidade e nela os termos possuem uma multiplicidade de elementos significativos que ultrapassam aquilo que foi fixado de maneira precisa e está aí presente na forma de uma explicação inteiramente definida. Daí se segue, segundo Gadamer, que quem quer compreender o que uma palavra diz, em uma língua viva, precisa buscar compreender o outro, isto é, precisa

4Cf. GADAMER, Hans-Georg. "Replik zu Hermeneutik und Ideologiekritik" [1971], in: Wahrheit und Methode: Ergänzungen; Register. 2. ed. Gesammelte Werke, Bd. 2. Tübingen: Mohr Siebeck, 1993, p. 260.

5 Cf. GADAMER, Hans-Georg. "Probleme der praktischen Vernunft" [1980], in: Wahrheit und Methode: Ergänzungen; Register, p. 324.

6 Cf. GADAMER, Hans-Georg. Wahrheit und Methode, p. 345. 
aceitar previamente que talvez não tenha razão. Somente assim a compreensão poderá ter uma continuidade ${ }^{7}$. Em outros termos, o pensamento precisa de distanciamento quando se trata não somente de repetir definições, mas de compreender aquilo que é mediado pela linguagem. Essa é uma ideia presente já na fenomenologia de Edmund Husserl e desenvolvida por Heidegger, com a sua proposta de destruição da linguagem da metafísica, consolidada em especial pela escolástica ${ }^{8}$. Embora Gadamer afirme que não há uma linguagem da metafísica, mas uma só linguagem, na qual a tradição metafísica formou seus conceitos, ele reconhece o esforço de Heidegger de reconduzir conceitos e expressões conceituais, que foram enrijecidos por aquela tradição, até o potencial linguístico que lhes é próprio. Para Gadamer, algo surge por meio da linguagem, ou seja, algo é compreendido e gera um efeito, naquele distanciamento de si, da palavra já encontrada, da decisão já tomada. Isso ocorre de maneira superior no diálogo, ao passo que na sua experiência é ultrapassada toda consciência subjetiva. $\mathrm{Na}$ experiência do diálogo também se vai além tanto da condição solitária do Dasein de ser lançado (Geworfenheit) ${ }^{9}$, como de decair (Verfallenheit) no mundo ${ }^{10}$, aspectos que são desenvolvidos pela analítica existencial de Heidegger ${ }^{11}$.

A fenomenologia hermenêutica não possuía interesse algum em tratar do saber prático que surge da escuta do outro, do diálogo. Mesmo os conceitos "ser-com" (Mitsein) e "cuidado" (Sorge) pouco têm a ver com a escuta ante um discurso. "Ser-com" é uma expressão sobre o Dasein, que justifica para a sua consciência que o outro é também (auch) Dasein ${ }^{12}$, mas representa um pensamento muito fraco do outro. Já "cuidado" significa muito mais "ser cuidadoso com o próprio ser" e "deixar o outro ser"13 do que de fato "ser dedicado ao outro"14. Desse modo, a hermenêutica somente tratou da questão do outro, e igualmente da presença do outro, como um problema que diz respeito a toda compreensão e assume especial centralidade na práxis humana, com a filoso-

7 Cf. GADAMER, Hans-Georg. "Frühromantik, Hermeneutik, Dekonstruktivismus" [1987], in: Hermeneutik im Rückblick, p. 130.

8 Cf. HEIDEGGER, Martin. Sein und Zeit. Tübingen: Max Niemeyer Verlag, 1967, p. 22.

9 Cf. DI CESARE, Donatella. Gadamer - Ein philosophisches Porträt. Tübingen: Mohr Siebeck, 2009, p. 234.

10 Cf. HEIDEGGER, Martin. Sein und Zeit, pp. 176-178.

11 Cf. GADAMER, Hans-Georg. “Frühromantik, Hermeneutik, Dekonstruktivismus”, p. 128.

$12 C f$. HEIDEGGER, Martin. Sein und Zeit, p. 118.

13 Cf. HEIDEGGER, Martin. Sein und Zeit, pp. 192-193.

$14 C f$. GADAMER, Hans-Georg. Die Lektion des Jahrhunderts: ein Interview von Riccardo Dottori. Münster: Lit, 2002, pp. 14-15. 
fia de Gadamer. Para ele, a tentativa de compreender já é desde o princípio o exercício de acolher, diante dos novos eventos e das perspectivas futuras, aquilo que ainda pode ser dito. A própria palavra "compreender" (Verstehen) em alemão já expressa isso: estar no lugar de alguém (für jemanden stehen), dirigir-se para os outros e falar pelos outros ${ }^{15}$. Isso significa tanto colocar-se incessantemente em questão, como relativizar os métodos que prometem uma constatação do sentido correto.

Se levarmos isso até as últimas consequências, fica claro que nem será possível uma autoconsciência no sentido de uma plena identificação consigo mesmo, nem o alcance de uma verdade absoluta. Esses limites representam no fundo a radicalidade e a confirmação daquela ideia de finitude defendida pela hermenêutica: ninguém pode conhecer plenamente a si mesmo, nem muito menos o outro. E em vez de isso representar uma falta, é antes de tudo uma constatação da nossa condição: nós não compreendemos no encontro solitário consigo mes$\mathrm{mo}^{16}$, mas no encontro com o outro, na diferença, como ocorre em um diálogo autêntico, em que há realmente uma troca de opiniões. Isso significa para Gadamer possuir linguagem: ser uns com os outros (Miteinander), em uma comunidade dialógica.

\section{A atualidade de Aristóteles: teoria e práxis}

Na verdade, tal distinção é uma atualização daquelas teses aristotélicas sobre o que nos caracteriza como propriamente humanos: o ser humano é um animal

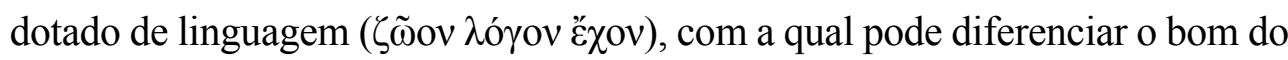

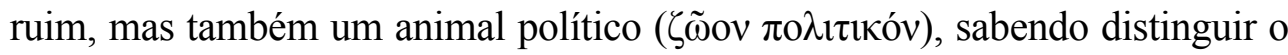
justo do injusto ${ }^{17}$. Para Gadamer, que a nossa compreensão dependa da linguagem, significa que os seus limites se encontram na contínua dependência do outro. Ela requer participação (Teilhabe) e, em um sentido mais autêntico, diálogo. Aqui teoria e prática estão imbricadas, bem como em toda a hermenêutica de Gadamer, de maneira implícita ou explícita. Na verdade, ele seguiu desde o começo o caminho da filosofia prática de Aristóteles, que no fundo, a despeito do que afirmam muitos dos críticos do estagirita, não se encontrava em oposi-

15Cf. GADAMER, Hans-Georg. "Frühromantik, Hermeneutik, Dekonstruktivismus", p. 129. $16 C f$. GADAMER, Hans-Georg. "Isolamento como sintoma de autoalienação" [1970], in: Elogio da teoria. Lisboa: Edições 70, 2001, p. 99.

17 Cf. ARISTOTELES. Politik. Hamburg: Meiner, 1990, p. 4, I, 1253a. 
ção à filosofia de Platão ${ }^{18}$. A ética do diálogo, como uma assimilação da ideia de sabedoria prática presente nas três éticas aristotélicas na forma da racionalidade prática ( $\varphi \rho o ́ v \eta \sigma ı \varsigma)$, mostra que, em realidade, este é um conceito platônico.

Para Gadamer, há uma aproximação entre a virtude que Platão concedeu ao dialético e os conceitos de phrónesis e phrónimos. Sua filosofia hermenêutica também está profundamente marcada pelas consequências teóricas daí decorrentes, que, por fim, conduz-nos até a discussão sobre a possibilidade de uma ética filosófica. Vale ressaltar, contudo, as diferenças que Gadamer aponta entre essas formas de pensamento e os pontos em que sua hermenêutica se põe em paralelo com uma ou outra. Platão, por exemplo, ao conferir ao dialético uma "excelência máxima", não fez uma diferenciação entre racionalidade teórica e prática e, assim, concedeu ao termo phrónesis um sentido amplo. Dialética para ele é phrónesis, mas também o são, em certo sentido, téchne ( $\tau \dot{\chi} \chi v \eta)$ e epistéme

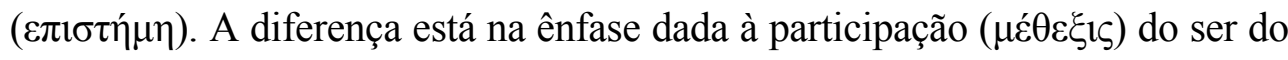
dialético no ser verdadeiro. Naquelas áreas o conhecimento é como um "ver

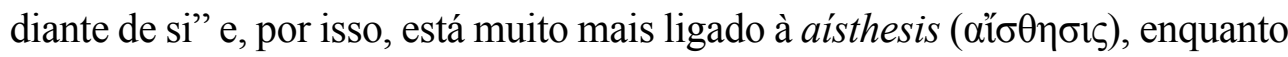

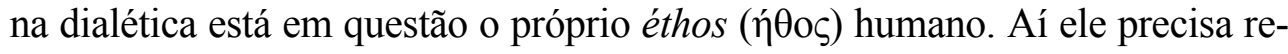
presentar de forma mais essencial a ideia de bem.

A partir disso se pode compreender por que a dialética socrático-platônica se aproxima, para Gadamer, muito mais de uma virtude, ao modo da phrónesis aristotélica e, como tal, não é ensinável, do que de um conhecimento puramente teorético. De modo similar, tradições éticas não se fundam tanto em ensinar e aprender, mas recorrem muito mais a exemplos e imitação. O fenômeno do ético ganha destaque mediante o modelo de uma figura ética. Se faz ética na medida em que se é, ou melhor, se busca ser ético. A todas as outras formas de comportamento é sugerida a imitação do exemplo do ético. Para Platão, ninguém se torna virtuoso mediante o aprendizado de um sistema normativo. Nisso consiste sua crítica à nova paideía $(\pi \alpha 1 \delta \varepsilon i ́ \alpha)$. Um mundo no qual as pessoas se tornaram incapazes de prestar esclarecimentos, porque já possuem uma orientação normativa sobre como devem proceder, só pode ser um mundo cuja educação é em verdade uma techné voltada para o sucesso e, assim, do conhecimento para se alcançar a maior fruição possível ${ }^{19}$.

18 Cf. GADAMER, Hans-Georg. Die Lektion des Jahrhunderts, pp. 11-13.

19 Cf. GADAMER, Hans-Georg. "Die Idee des Guten zwischen Plato und Aristoteles", in: Grieschische Philosophie III: Plato im Dialog. Gesammelte Werke, Bd. 7. Tübingen: Mohr Siebeck, 1991, pp. 152-154. 
Quando se trata especialmente da experiência ética e política parece que o fator determinante para Platão é algo quase divino ( $\theta$ cía $\mu$ oí $\rho \alpha$ ), isto é, sobre o qual não temos conhecimento. É por isso que Sócrates declara ser o conhecimento do não conhecimento a verdadeira sabedoria humana. Aquele que muito sabe sobre si mesmo já percebeu a urgência de contemplar a própria alma, em busca de um vestígio que fora esquecido. Esse é o sentido da teoria da anamnese (à $\alpha \dot{\mu} \mu \nu\rceil r \varsigma)$ de Platão, que também está presente na dialética do diálogo. Todo o saber se assemelha ao conhecimento que temos de nós mesmos, e este está para além do lógos ( $\mu \varepsilon \tau \alpha$ ó $\lambda o ́ \gamma o v$ ). Segundo Gadamer, isso contrapõe o discurso usual de que há um intelectualismo forte nos diálogos platônicos no

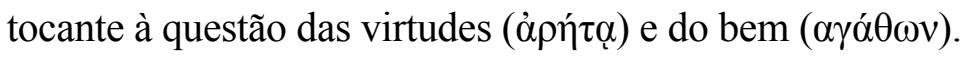

Aristóteles reconheceu esse lado positivo da dialética socrático-platônica, mesmo que tenha se colocado na posição de corrigir a suposta equiparação entre virtude e conhecimento presente nos diálogos. Com tal crítica, ele obteve o conceito de éthos, dando assim origem a novas indagações dentro do âmbito intitulado "filosofia prática". Ademais, o tipo de texto aristotélico está de acordo com o seu conteúdo, isto é, com as distinções que trazem uma fixação conceitual da compreensão socrático-platônica da unidade de todas as virtudes e visam resguardar a questão do bem das ambiguidades e aporias, que surgem com a arte platônica do diálogo socrático. Uma dessas distinções foi aquela

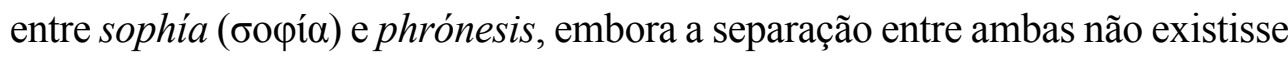
no uso da língua grega. Contudo, para Gadamer, apesar de isso ter representado uma perda do potencial linguístico que há na palavra viva, foi ao mesmo tempo um ganho para a transmissão do sentido da ética filosófica.

Os conceitos empregados na hermenêutica filosófica pertencem muito mais à tradição platônica do que aristotélica, como, por exemplo, mímesis ( $\mu$ í $\mu\rceil \tau \varsigma$ ), méthexis, anámnesis. Gadamer também aprendeu com Platão, por meio dos diálogos socráticos, que a estrutura do monólogo do saber científico, por exemplo, jamais alcançará os intentos do pensamento filosófico, porque a Filosofia se desenvolve constantemente no fenômeno específico do outro e, em especial, no diálogo com a sua própria história ${ }^{20}$. Todavia, quando se tratava de pensar a análise do autoconhecimento como um modo de comportamento do ser humano, capaz de conduzir à organização da vida na direção de um bem comum, Gadamer preferiu dar ênfase ao modo como Aristóteles integrou à sua ética a tradição socrático-platônica.

20Cf. GADAMER, Hans-Georg. "Zwischen Phänomenologie und Dialektik: Versuch einer Selbstkritik”, in: Wahrheit und Methode: Ergänzungen; Register, pp. 12-13. 
A hermenêutica gadameriana movimentou-se desde o princípio na proximidade entre teoria e práxis, que já estava presente no diálogo entre Platão e Aristóteles através do conceito de phrónesis. As teses de que Platão desenvolvera a ideia de "bem" não como a base de uma perspectiva ontológica, mas como uma pergunta pelo ético no sentido próprio, e Aristóteles não com a intenção maior de criticar a teoria das ideias, mas de fornecer uma base para a sua teoria da phrónesis ${ }^{21}$, impulsionaram Gadamer a estabelecer cada vez mais uma ligação entre a sua hermenêutica e a filosofia prática, até o ponto de aquela se transformar em uma forma atualizada desta. O fundamento para essa concreção já se encontra em Verdade e método através da interpretação da ética aristotélica ${ }^{22}$.

Nessa ocasião, Gadamer pensa que o problema da compreensão encontra-se em um âmbito muito similar àquele no qual Aristóteles pôs os modos de comportamento, isto é, cujas regras dependem da mutabilidade e da limitação do estatuto humano e do modo do ser humano se comportar. Para que algo seja compreendido por meio da linguagem, a compreensão precisa estar atuando no seu modo variável de escuta do outro, ou seja, linguagem e diálogo precisam ser equiparados. Já o éthos entra de acordo com a phrónesis, na medida em que algo

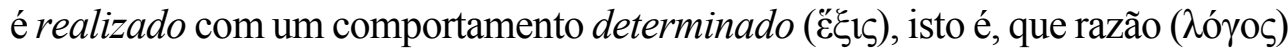
e virtude são submetidas a uma situação de igualdade. Atuando de certo modo, tem-se a chance de compreender e evitar mal-entendidos. Comportando-se de certo modo, alguém pode avaliar uma situação e agir aí de maneira correta ${ }^{23}$.

Essa é uma primeira imagem de como a phrónesis, e com ela a sabedoria prática, foi escolhida por Gadamer como modelo de sua hermenêutica. Desse modo, ao mesmo tempo que o filósofo se aproximou da filosofia prática de Aristóteles, ele igualmente se afastou de uma ciência produtiva, de uma ciência pura, mas também de uma filosofia estritamente teórica, como foi a metafísica para o estagirita ${ }^{24}$. Isso significa que Gadamer não segue Aristóteles sem restrições e em todo o caso, mas apenas no que diz respeito à sua filosofia prática.

21 Cf. GADAMER, Hans-Georg. Die Lektion des Jahrhunderts, p. 17.

22 Cf. GADAMER, Hans-Georg. Hermeneutik - Ästhetik-praktische Philosophie: Hans-Georg Gadamer im Gespräch. Hrsg. von Carsten Dutt. 2. ed. Heidelberg: Winter, 1995, p. 65.

23 Cf. GADAMER, Hans-Georg. Wahrheit und Methode, pp. 317-318.

$24 C f$. RESE, Friederike. "Phronesis als Modell der Hermeneutik", in: FIGAL, Günter (Hrsg.). Hans-Georg Gadamer - Wahrheit und Methode. Berlin: Akademie Verlag, 2007, p. 127. 
Todavia, é possível questionar se, ao dar ênfase à teoria da phrónesis, ele julgou fazê-lo porque interpretou mal o pensamento de Aristóteles, optou por se distanciar de toda a reflexão teórica sobre a práxis, ou incorporou à sua hermenêutica tanto a filosofia teórica como a filosofia prática aristotélica ${ }^{25}$. Em primeiro lugar, gostaríamos de mostrar como Gadamer compreende essa relação entre teoria e práxis. Pensamos que somente depois disso nos é permitido falar sobre os desdobramentos da interpretação da filosofia hermenêutica sobre a questão da racionalidade prática e, assim, ver em que sentido temos condições de falar em um encurtamento ou ampliação da filosofia aristotélica.

Gadamer tenta mostrar reiteradas vezes como a teoria não se encontra em oposição à atividade prática, ou melhor, à práxis, mas ela mesma é a mais elevada presentificação da práxis, o mais elevado modo de ser do ser humano ${ }^{26}$. Nós dizemos que temos uma teoria, quando somos absorvidos (aufgehen) por algo, ao nos demorarmos (verweilen) observando-o e sentirmos certo orgulho daquilo que alcançamos ${ }^{27}$. É como uma forte persuasão íntima de que naquele momento realmente captamos algo e isso pode nos animar, mover e preencher com um sentimento de felicidade. Essa é, segundo Gadamer, um tipo de vivência rara e, além de tudo, limitada pelas nossas experiências. Nas suas palavras:

Nós somos sempre reduzidos entre o dia e a noite, entre o estar desperto e o mergulho no sono. Nós sabemos quanto nos custa dominar, quando estamos despertos, nossas inclinações, tentações, distrações. A teoria é em verdade tudo o que nos é privado nessa mais alta vigília da demora e absorção (GADAMER, 2000, p. 9).

Contudo, o único modo de atingirmos algo como a teoria é enfrentando paulatinamente e continuamente as situações que restringem a nossa formação de conceitos. Nesse sentido, o saber tem, antes de tudo, sua origem e, depois, uma dependência naquilo que nos acontece em um nível prático. Essas são caracte-

$25 \mathrm{Cf}$. BERTI, Enrico. "Gadamer and the reception of Aristotle", in: Revista Portuguesa de Filosofia, vol. 56 / 3-4, jul-dez 2000, pp. 345-360.

$26 C f$. GADAMER, Hans-Georg. "Über die Möglichkeit einer philosophischen Ethik”, [1963], in: Neuere Philosophie II: Probleme, Gestalten. Gesammelte Werke, Bd. 4. Tübingen: Mohr Siebeck, 1999p. 175.

27 Cf. GADAMER, Hans-Georg. "Hermeneutik - Theorie und Praxis" [1996], in: Hermeneutische Entwürfe: Vorträge und Aufsätze. Tübingen: Mohr Siebeck, 2000, p. 8. 
rísticas já presentes na descrição da base teórica para as ações éticas ou mesmo para a práxis como um todo, a phrónesis, das quais Gadamer se apropriou para distinguir toda forma de teoria. Há saber quando nós nos comportamos de um modo ao invés de outro, quando nós mostramos que somos de um modo e não de outro. O conhecimento que temos existe também em virtude daquilo que somos. É desse modo que o saber e a exigência do "comportar-se assim ou assim" estão próximos um do outro. Já para Aristóteles, seja teoria ou práxis, ambos estão guiados pelo nous (voũ $)^{28}$.

Em várias passagens o filósofo grego compara a inteligência (vółбıs) humana com a divina. A nóesis do ser humano seria diferente da nóesis dos deuses principalmente porque aquela, além de não ser contínua, lida com a exaustão que envolve a passagem da potência ao ato. Apesar disso, ela é tanto a função ("̌ppov) dos deuses como do ser humano. Quando praticamos a contemplação ( $\theta \varepsilon \omega \rho i ́ \alpha)$, aproximamo-nos do modo de ser divino ${ }^{29}$ e contribuímos espontaneamente com o nosso ambiente natural e social e a nossa própria felicidade. Seria, então, a contemplação suficiente para vivermos bem?

Para os filósofos gregos não. É por isso que entre eles fazia sentido discutir sobre a ideia de um saber amplo, de Filosofia. Com o surgimento das ciências modernas do século XVII, ou seja, com o seu novo modelo de experiência e ideal de método, o sentido lato de Filosofia começou a desaparecer. Isso ocorreu simultaneamente à separação do saber teórico da sua conexão com o nosso processo de formação e a nossa vida como um todo. Se antes a teoria era pensada também em relação ao nosso saber partilhado linguisticamente e socialmente, com a ideia de objetividade foi criada uma tensão entre o que consideramos saber humano, por um lado, e experiência humana, por outro ${ }^{30}$.

Mesmo o conceito de "sistema", que apareceu na terminologia filosófica no final do século XVII, designando a mediação entre a nova ciência e a metafísica mais antiga, não possuía o mesmo sentido dado por Aristóteles, isto é, de uma mútua participação entre teoria e práxis. É claro que as ciências modernas transformaram o nosso mundo e toda a nossa compreensão de mundo. Passamos a ter outras formas de comunicação e, com isso, novas tarefas e problemas. Por

$28 C f$. GADAMER, Hans-Georg. "Hermeneutik - Theorie und Praxis", pp. 10-11; GADAMER, Hans-Georg. "Die Idee der praktischen Philosophie" [1983], in: Hermeneutik im Rückblick, p. 243.

29 Cf. PETERS, F. E. Termos filosóficos gregos: um léxico histórico. 2. ed. Trad. pt. Beatriz Rodrigues Barbosa. Lisboa: Fundação Caloustre Gulbenkian, 1983, p. 163.

30 Cf. GADAMER, Hans-Georg. "Bürger zweier Welten" [1985], in: Hermeneutik im Rückblick, pp. 228-229. 
outro lado, a imagem conceitual e linguística de nossa tradição cultural, que remonta à dialética e à metafísica gregas, além de fazer parte da nossa formação, ainda determina a nossa autocompreensão ${ }^{31}$.

O mesmo vale aqui para a retomada do pensamento grego pela hermenêutica de Gadamer. Apesar de a filosofia prática ter significado para os gregos algo que tem a ver com o modo de expressão deles e as questões por eles formuladas, não só os conceitos que dela herdamos e o seu uso semântico ainda podem ter certa significação para nós, como muitos dos comportamentos humanos e a tentativa de compreendê-los não sofreram muitas alterações. Há problemas oriundos da convivência humana, como abuso de poder, por exemplo, que já existia entre os gregos e continua existindo em nossos dias.

Conforme Gadamer, Aristóteles permanece sendo seu parceiro privilegiado de diálogo, porque ele apresenta para nós o ideal de razão, com o qual podemos reagir contra o ideal dos modernos de um mundo dominado pelo saber e poder. Isso significa que ele nos traz o ideal de um mundo racionalmente ordenado e compreensível, no qual nós temos de viver ${ }^{32}$. A sua ideia de filosofia prática traz uma tese metafísica fundamental: o ser humano possui lógos e, por isso, ele, como cidadão livre, pode e precisa fazer escolhas ( $\pi \rho 0 \alpha i ́ \rho \varepsilon \sigma 1 \varsigma)$. Isso significa que ele precisa encontrar o "bem" a cada vez que se depara com uma situação concreta e, para tanto, tem que saber como fazê- $-o^{33}$. Refletimos sobre a filosofia prática, portanto, não para que saibamos meramente quais ações são boas, mas sim para que cheguemos a ser bons.

Daí chegamos à seguinte pergunta: A reflexão sobre a ação precisa realmente da Filosofia? Sim, porque esta pode nos auxiliar na formação de nossa racionalidade prática. Se alguém já é propenso a fazer o bem diante de uma situação concreta, sê-lo-á efetivamente se possuir o saber universal dos conceitos. A phrónesis pressupõe educação, isto é, exercício e formação madura do éthos. Não há modos de comportamento voltados para o bem sem lógos e, consequentemente, não há racionalidade prática sem racionalidade teórica. A relação entre ambas é de participação mútua e não hierárquica ${ }^{34}$. Ao construir a Ética a Nicômaco, Aristóteles quis enfatizar essa relação ${ }^{35}$.

31Cf. GADAMER, Hans-Georg. "Bürger zweier Welten", p.230.

32 Cf. GADAMER, Hans-Georg. "Die Idee der praktischen Philosophie", p. 246.

33 Cf. GADAMER, Hans-Georg. "Die Idee der praktischen Philosophie", p.238.

34 Cf. GADAMER, Hans-Georg. "Die Idee der praktischen Philosophie", pp. 239-240.

35 Cf. ARISTOTELES. Nikomachische Ethik VI. Hrsg. übers. von Hans-Georg Gadamer. Frankfurt am Main: Vittorio Klostermann, 1998, pp. 54-58. 
O sentido de defender uma filosofia prática é dar ao filósofo a possibilidade de esclarecer conceitualmente e servir teoricamente como um mediador instruído do conflito que se cria em torno de situações que requerem uma escolha. Segundo Gadamer, a obra prima de Aristóteles foi justamente a filosofia prática, porque ela aponta para o aberto, isto é, ela tanto aponta para a verdade da experiência humana como um todo, como pergunta sobre como podemos chegar a pôr conceitos em prática. Ele dividiu a filosofia em teórica e prática, não por vê-las como domínios separados, mas para enfatizar a sua contribuição: manter a abertura para novas perspectivas teóricas, cujo potencial já se encontra presente na própria variabilidade de elementos significativos da língua viva ${ }^{36}$.

\section{Conclusão}

Com base em um estudo aprofundado da filosofia prática grega, Gadamer teve a oportunidade especial de atualizar, por um lado, a teoria da phrónesis aristotélica e encontrar, por outro lado, um diálogo com a tradição que contribuísse para apresentar a amplitude dos propósitos da sua hermenêutica filosófica. Mostrando como a compreensão é tanto teórica como prática, ele pôde fazer frente à aplicação desmedida do nosso poder científico e técnico. Ele é enfático quando defende que empregar conceitos ou métodos de investigação científica à reflexão de todos os nossos comportamentos e escolhas restringe o nosso potencial de lidar de outras maneiras com certas experiências, talvez mais de acordo com a nossa condição humana e o respeito a esta dentro de uma comunidade linguística.

Os gregos não tiveram que lutar contra esse encurtamento do conceito de racionalidade, que domina a ciência e a filosofia modernas. Eles simplesmente tomaram para si a imensa tarefa de explorar um solo linguístico nunca antes penetrado. Já a razão pela qual Gadamer desenvolve a sua filosofia prática é para mostrar mais um vez, na medida em que isso se tornou necessário, especialmente nos séculos XX e XXI, que ainda nos podemos voltar para os conceitos, na tentativa de compreendermos quem somos, entendermos uns aos outros e, assim, fazermos desse mundo um lugar melhor. Parece que é aí que a Filosofia deixa de ser, em uma época de imagens de mundo especializadas, uma relíquia de um tempo passado, fuga irresponsável de sonhos desfeitos ou imaturidade do espírito cognoscente, para reafirmar a sua "serventia": a busca incansável pela verdade e pelo "viver bem".

$36 C f$. GADAMER, Hans-Georg. "Frühromantik, Hermeneutik, Dekonstruktivismus", p. 130. 
ARISTOTELES. Nikomachische Ethik VI. Hrsg. übers. von Hans-Georg Gadamer. Frankfurt am Main: Vittorio Klostermann, 1998.

Politik. Hamburg: Meiner, 1990.

BERTI, Enrico. "Gadamer and the reception of Aristotle", in: Revista Portuguesa de Filosofia, vol. 56 / 3-4, jul-dez 2000, pp. 345-360.

DI CESARE, Donatella. Gadamer - Ein philosophisches Porträt. Tübingen: Mohr Siebeck, 2009.

GADAMER, Hans-Georg. "Hermeneutik als praktische Philosophie", in: SCHÖNHERR-MANN, Hans-Martin (Hrsg.). Hermeneutik als Ethik. München: Wilhelm Fink Verlag, 2004.

Die Lektion des Jahrhunderts: ein Interview von Riccardo Dottori. Münster: Lit, 2002.

Elogio da teoria. Lisboa: Edições 70, 2001.

Grieschische Philosophie III: Plato im Dialog. Gesammelte Werke, Bd. 7. Tübingen: Mohr Siebeck, 1991.

.Hermeneutik - Ästhetik - praktische Philosophie: Hans-Georg Gadamer im Gespräch. Hrsg. von Carsten Dutt. 2. ed. Heidelberg: Winter, 1995.

Hermeneutik im Rückblick. Gesammelte Werke, Bd. 10. Tübingen: Mohr Siebeck, 1999.

.Hermeneutische Entwürfe: Vorträge und Aufsätze. Tübingen: Mohr Siebeck, 2000.

.Neuere Philosophie II: Probleme, Gestalten. Gesammelte Werke, Bd. 4. Tübingen: Mohr Siebeck, 1999.
Wahrheit und Methode: Ergänzungen; Register. 2. ed. Gesammelte Werke, Bd. 2. Tübingen: Mohr Siebeck, 1993.

Wahrheit und Methode: Grundzüge einer philosophischen Hermeneutik. 6. ed. Gesammelte Werke, Bd. 1. Tübingen: Mohr Siebeck, 1990.

HEIDEGGER, Martin. Sein und Zeit. Tübingen: Max Niemeyer Verlag, 1967.

PETERS, F. E. Termos filosóficos gregos: um léxico histórico. 2. ed. Trad. pt. Beatriz Rodrigues Barbosa. Lisboa: Fundação Caloustre Gulbenkian, 1983.

RESE, Friederike. "Phronesis als Modell der Hermeneutik", in: FIGAL, Günter (Hrsg.). Hans-Georg Gadamer Wahrheit und Methode. Berlin: Akademie Verlag, 2007.

SCHLEIERMACHER, Friedrich D. E. Hermenêutica e crítica. Trad. br. Aloísio Ruedell. Rev. Paulo R. Schneider. Ijuí: Editora Unijuí, 2005.

VATTIMO, Gianni. "Comprender el mundo - transformar el mundo", in: HABERMAS, J.; RORTY, R.; VATTIMO, G. (et.al.). "El ser que puede ser compreendido es lenguage". Homenaje a Hans-Georg Gadamer. Madrid: Editora Sintesis, 2003.

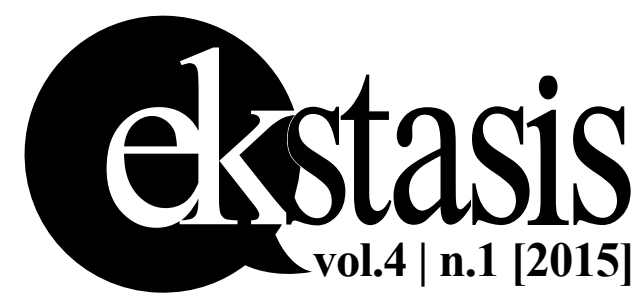

